\title{
STUDI DESKRIPTIF TENTANG KADAR DEBU PADA PERTUKANGAN KAYU PK BODAS KUSEN KABUPATEN PURBALINGGA
}

\author{
Puput Hargiani 1), Agus Subagiyo ${ }^{2)}$
}

\author{
Poltekkes Kemenkes Semarang, Poltekkes Kemenkes Semarang
}

\begin{abstract}
Abstrak
Lingkungan yang sehat perlu dilakukan pengawasan agar terhindar dari dampak negatif terhadap kesehatan maupun keselamatan. Salah satu diantara kualitas lingkungan yang sehat adalah terhindar dari pencemaran udara dengan zat pencemaran yaitu debu. Dngan ukurannya yang sangat kecil,debu dapat menyelinap dan diam lama dalam perabotan rumah tangga yang apabila dibiarkan maka dapat berbahaya bagi kesehatan, diantaranya iritasi pada mata, sering bersin-bersin, iritasi pada kulit dan gangguan pernapasan. Tujan dari penelitian ini adalah untuk mengetahui kadar debu pada Pertukangan Kayu PK Bodas Kusen dan permukiman terdekat Pertukangan Kayu PK Bodas Kusen.Metode penelitian yang digunakan pada penelitian ini adalah deskriptif, yaitu suatu metode penelitian yang dilakukan dengan tujuan untuk membuat gambaran suatu keadaan secara objektif dan memecahkan atau menjawab permasalahan yang sedang dihadapi pada permasalahan sekarang.Hasil penelitian pengukuran kadar debu pada pertukangan kayu PK Bodas Kusen dengan menggunakan Dusttrek selama pengukura 15 menit adalah $0,491 \mathrm{mg} / \mathrm{m}^{3}$ dan setelah dikonversikan ke 8 jam adalah $15,712 \mathrm{mg} / \mathrm{m}^{3}$. Sedangkan hasil penelitian pengukuran kadar debu pada permukiman yang terdekat dengan pertukangan kayu PK Bodas Kusen selama 15 menit pengukuran adalah didapatkan hasil tertinggi sebesar $0,362 \mathrm{mg} / \mathrm{m}^{3}$ atau $362 \mu \mathrm{g} / \mathrm{m}^{3}$, hasil terendah sebesar $0,302 \mathrm{mg} / \mathrm{m}^{3}$ atau $302 \mu \mathrm{g} / \mathrm{m}^{3}$ dan didapatkan hasil rata-rata sebesar $0,317 \mathrm{mg} / \mathrm{m}^{3}$ atau $317 \mu \mathrm{g} / \mathrm{m}^{3}$ sedangkan setelah dikonversikan ke 24 jam di dapatkan hasil tertinggi sebesar yaitu sebesar $30,432 \mathrm{mg} / \mathrm{m}^{3}$ atau $30.432 \mu \mathrm{g} / \mathrm{m}^{3}$, hasil terendah sebesar $28,991 \mathrm{mg} / \mathrm{m}^{3}$ atau $28.991 \mu \mathrm{g} / \mathrm{m}^{3}$ dan didapatkan hasil rata-rata sebesar $30,432 \mathrm{mg} / \mathrm{m}^{3}$ atau $30.432 \mu \mathrm{g} / \mathrm{m}^{3}$.Masyarakat seharusnya membersihkan rumah dan perabotnya minimal 2 kali sehari dan menyiram halaman rumah untuk mengurangi debu yang berterbangan, sedangkan untuk pihak Pertukngan Kayu PK Bodas Kusen seharusnya menambah fasilitas penghisap debu yang sifatnya lokal dengan cara didekatkan ke sumbernya dan menyediakan APD untuk para pekerja.
\end{abstract}

Kata kunci: Kayu; Kadar Debu

\begin{abstract}
A Healthy environment needs supervision so it will be spared from negative effect to health and safety live. One of the quality environment is environment which is free from air pollution with the dust as the contaminant. Dust can sneak and stay still for a long period time on house furniture with its really small size. If the condition is ignored it will cause some health problems such as eye irritation, sneezing, skin irritation and respiratory disorder. The purpose of this study research is to know the dust contenten in carpenter of PK Bodas Kusen.The method of thid research is description method. It is a method that use to describe a situation subjectively and to solve or answer that problems that encountered in this research.The result of this research from the measurement of dust content of PK Bodas Kusen with dusttrack for 15 minutes is $0,491 \mathrm{mg} / \mathrm{m}^{3}$ and after it is conversed to 8 hours it be $15,712 \mathrm{mg} / \mathrm{m}^{3}$. While the result of research of measurement of dust content in settlement nearest to wood carving of PK Bodas Kusen for 15 minutes measurement is got the highest result $0,362 \mathrm{mg} / \mathrm{m}^{3}$ or $362 \mu \mathrm{g} / \mathrm{m}^{3}$, the lowest result is $0,302 \mathrm{mg} / \mathrm{m}^{3}$ or $302 \mu \mathrm{g} / \mathrm{m}^{3}$ and got result average of $0.317 \mathrm{mg} / \mathrm{m}^{3}$ or $317 \mu \mathrm{g} / \mathrm{m}^{3}$ whereas after converted to 24 hours in get the highest result that is equal to $30,432 \mathrm{mg} / \mathrm{m}^{3}$ or $30,432 \mu \mathrm{g} / \mathrm{m}^{3}$, the lowest result of $28,991 \mathrm{mg} / \mathrm{m}^{3}$ or $28,991 \mu \mathrm{g} / \mathrm{m}^{3}$ and obtained average yield of $30.432 \mathrm{mg} / \mathrm{m}^{3}$ or $30,432 \mu \mathrm{g} / \mathrm{m}^{3}$.The people should clean the house and the furniture twice a day, and watering the yard to reduce the dust in the air. The carpenter of PK Bodas Kusen should add the facilities of vacuum cleanerand provide APD for the works.
\end{abstract}

Key words : Carpente; dust concentration

1) E-mail: puputhargiani555@gmail.com

2) E-mail: agusgiyo@yahoo.co.id 


\section{Pendahuluan}

Pembangunan kesehatan bertujuan untuk meningkatkan kesadaran, kemauan, dan kemampuan hidup sehat bagi setiap orang agar terwujud derajat kesehatan masyarakat yang setinggi-tingginya, sebagai investasi bagi pembangunan sumber daya manusia yang produktif secara sosial dan ekonomis. Mewujudkan tujuan tersebut tidak hanya pada peningkatan sarana dan prasarana kesehatan, tetapi juga kualitas lingkungan. (UU Nomor 36 Tahun 2009).

Udara merupakan faktor yang penting dalam kehidupan, namun dengan meningkatnya pembangunan fisik kota dan pusat-pusat industri, kualitas udara telah mengalami perubahan. Udara yang dulunya segar kini kering dan kotor. (Moestikahadi Soedomo, 2001 h, 3)

Perubahan lingkungan udara pada umumnya disebabkan pencemaran udara, yaitu masuknya zat pencemar (berbentuk gas-gas dan partikel kecil/aerosol) kedalam udara. Masuknya zat pencemar kedalam udara dapat secara alamiah, misalnya asap kebakaran hutan, akibat gunung berapi, debu meteorit dan pancaran garam dari laut, juga sebagian besar disebabkan oleh kegiatan manusia, misalnya akibat aktivitas transportasi, industri, pembuangan sampah baik akibat proses dekomposisi ataupun pembakaran serta kegiatan rumah tangga. (Moestikahadi Soedomo, 2001 h, 3)

Disadari atau tidak, beberapa kegiatan manusia dapat mengotori udara. Secara alami, sebenarnya alam (termasuk udara) memiliki mekanisme pembersih diri, antara lain siklus hidrologi yang dapat mencuci atmosfer. Namun kadang kala bahan cemaran pengotor udara melebihi kemampuan alam untuk membersihkan diri. Keadaan tersebut menjadikan udara tercemar, kotor, tidak mampu memenuhi fungsi dan tidak layak untuk mendukung suatu kehidupan termasuk manusia. Dalam waktu yang lama makhluk hidup berusaha mengadaptasi kondisi tersebut dan berusaha untuk membentuk suatu keseimbangan. (Tri Cahyono, 2017 h, 63)

Secara teoritis, pencemaran udara dapat diartikan adanya gas, partikulat cair, padatan, energi, atau komponen lain yang melebihi batas tertinggi atau terendah, atau yang seharusnya bahan ada namun tidak ada atau sebaliknya. (Tri Cahyono, 2017 h, 65)

\section{Bahan dan Metode}

Metode penelitian yang digunakan pada penelitian ini adalah deskriptif, yaitu suatu metode penelitian yang dilakukan dengan tujuan untuk membuat gambaran suatu keadaan secara objektif, dan memecahkan atau menjawab permasalahan yang sedang dihadapi pada permasalahan sekarang.

Subyek penelitian ini adalah Kadar Debu pada Pertukangan Kayu PK Bodas Kusen dan Permukiman terdekat yang ada di Desa Bodaskarangjati Kecamatan Rembang Kabupaten Purbalingga.

\section{III.Hasil}

A. Gambaran Umum Pertukangan Kayu

1. Keadaan Geografis

Keadaan geografis Pertukangan Kayu PK. Bodas Kusen di Desa Bodaskarangjati Kecamatan Rembang Kabupaten Purbalingga adalah sebagai berikut:

a. Batas-batas Pertukangan Kayu PK. Bodas Kusen di Desa

Bodaskarangjati

KecamatanRembang

KabupatenPurbalingga.

1) Sebelah Utara

Permukiman RT 2 RW 5

2) Sebelah Selatan

Mushola Al - Ikhlas

3) Sebelah Barat

Permukiman RT 2 RW 5

4) Sebelah Timur

Depot Air Minum Isi Ulang

Bio Samfalaf dan

Permukiman RT 3 RW 4

b. Luas Pertukangan Kayu PK. Bodas Kusen di Desa Bodaskarangjati Kecamatan Rembang Kabupaten Purbalingga adalah $287 \mathrm{~m}^{2}$.

2. Pekerja

Jumlah pekerja yang terdapat pada Pertukangan Kayu PK. Bodas Kusen di Desa Bodaskarangjati Kecamatan Rembang Kabupaten Purbalingga adalah sebanyak 6 orang. Yang terdiri dari 4 pekerja yang bekerja menggunakan mesin dan 2 pekerja manual yang bekerja menggunakan tangan dan bekerja mengantarkan barang yang sudah jadi ke konsumen. 
3. Prosedur kerja

Pertukangan Kayu PK Bodas Kusen di Desa Bodaskarangjati Kecamatan Rembang Kabupaten Purbalingga tidak memiliki prosedur kerja.

4. Jam kerja

Jam kerja pada Pertukangan Kayu PK Bodas Kusen di Desa Bodaskarangjati Kecamatan Rembang Kabupaten Purbalingga dimulai dari pukul 07.00 WIB 17.00 WIB. Selain itu juga terdapat jeda waktu buat istirahat para pekerjanya. Dan waktu istirahat yang diberikan hanya pada waktu sholat dzuhur dan ashar, yaitu paling lama 30 menit.

5. Alat kerja

Adapun alat kerja yang digunakan pada Pertukangan Kayu PK. Bodas Kusen di Desa Bodaskarangjati Kecamatan Rembang Kabupaten Purbalingga adalah diantaranya sebagai berikut:
a. Cyrcle
b. Gerinda
c. Mesin bobok
d. Amplas
e. Meteran
f. Pensil
g. Propil
h. dll

6. Bahan kerja

Bahan kerja yang digunakan pada Pertukangan Kayu PK Bodas Kusen di Desa Bodaskarangjati Kecamatan Rembang Kabupaten Purbalingga diantaranya adalah:
a. Kayu
b. Lem kayu
c. Paku

7. Kegiatan pertukangan kayu

Kegiatan pertukangan kayu di Pertukangan Kayu PK Bodas Kusen di Desa Bodaskarangjati Kecamatan Rembang Kabupaten Purbalingga adalah sebagai berikut:

a. Membelah kayu sesuai dengan pola dan ukuran yang telah ditentukan menggunakan mesin cyrcle

b. Menggerinda

c. Membuat lubang menggunakan mesin bobok

d. Mengamplas

e. Membuat purus

f. dll

8. Kapasitas produksi

Kapasitas produksi yang dihasilkan pertukangan kayu PK Bodas Kusen dalam setiap bulannya sekitar 120 buah pintu dan 120 buah jendela.

9. Gambaran umum permukiman

Pertukangan Kayu PK Boodas

Kusen di Desa Boodaskarangjati Kecamatan Rrembang Kabupaten Purbalingga terletak di tengahtengah permukiman RT 2 RW 5 dan RT 3 RW 4. Pada RT 2 RW 5 terdiri dari $108 \mathrm{KK}$ dengan jumlah warga sebanyak 360 warga. Sedangkan pada RT 3 RW 4 terdiri dari 89 KK dengan jumlah warga sebanyak 170 warga.

a. Batas-batas terdekat

1) Sebelah Utara :

Permukiman RT 2 RW 5

2) Sebelah Selatan : Mushola $\mathrm{Al}$ - Ikhlas

3) Sebelah Barat : Permukiman RT 2 RW 5

4) Sebelah Timur : Depot Air Minum Isi Ulang Bio Samfalaf danPermukiman RT 3 RW 4.

b. Jumlah penduduk di Desa

Bodaskarangjati adalah 3.833

jiwa, dengan perincian yaitu

1.880 jiwa penduduk laki-laki

dan 1.953 jiwa penduduk

perempuan tergabung dalam

$1.2262 \mathrm{KK}$.

Sasaran penelitian yaitu di permukiman paling terdekat denga pertukangan kayu PK Bodas Kusen Desa Bodaskarangjati Kecamatan Rembang Kabupaten Purbalingga yaitu pada RT 2 RW 5 dan RT 3 RW 4, karena pertukangan kayu PK Bodas Kusen terletak di tengahtengah permukiman tersebut. Pada RT 2 RW 5 Desa Bodaskarangjati dengan jumlah penduduk 360 jiwa yang terdiri dari 182 jiwa laki-laki dan 178 jiwa perempuan serta 108 KK. Sedangkan pada RT 3 RW 4 jumlah penduduknya sebesar 166 jiwa yang terdiri dari 75 jiwa lakilaki dan 91 jiwa perempuan serta 52 KK.

a. Jumlah penduduk di RT 2 RW 5 dan RT3 RW 4 Desa Bodaskarangjati menurut umur Tabel 4.1: Jumlah PendudukMenurut Umur Di Desa Bodaskarangjati RT 2 RW 5 Kabupaten Purbalingga Tahun 2018 


\begin{tabular}{rrrr}
\hline No & $\begin{array}{r}\text { Kategori } \\
\text { umur } \\
\text { tahun) }\end{array}$ & $\begin{array}{r}\text { Jumlah } \\
\text { (jiwa) }\end{array}$ & $(\%)$ \\
\hline 1 & $0-9$ & 34 & 9,44 \\
2 & $10-20$ & 57 & 15,83 \\
3 & $21-30$ & 50 & 13,88 \\
4 & $31-40$ & 77 & 21,38 \\
5 & $41-50$ & 59 & 16,38 \\
6 & $51-60$ & 41 & 11,38 \\
7 & $61-70$ & 24 & 6,66 \\
8 & $>71$ & 18 & 5,00 \\
\hline & Jumlah & 360 & 100,00 \\
\hline
\end{tabular}

Sumber: Data dari Ketua RW 5, tahun 2018

Berdasarkan tabel 4.1 dapat dilihat bahwa penduduk yang paling banyak adalah penduduk dengan kategori 31 - 40 tahun yaitu sebanyak 77 jiwa $(21,38 \%)$ dan yang sedikit yaitu dengan kategori >71 tahun sebanyak 18 jiwa (5\%).

Tabel 4.2: Jumlah Penduduk Menurut Umur Di Desa Bodaskarangjati RT 3 RW 4 Kabupaten Purbalingga Tahun 2018

\begin{tabular}{rrrr}
\hline No & $\begin{array}{r}\text { Kategori } \\
\text { umur } \\
\text { (tahun) }\end{array}$ & $\begin{array}{r}\text { Jumlah } \\
\text { (jiwa) }\end{array}$ & $(\%)$ \\
\hline 1 & $0-9$ & 16 & 9,63 \\
2 & $10-20$ & 28 & 16,86 \\
3 & $21-30$ & 23 & 13,85 \\
4 & $31-40$ & 23 & 13,85 \\
5 & $41-50$ & 24 & 14,45 \\
6 & $51-60$ & 14 & 8,43 \\
7 & $61-70$ & 22 & 13,25 \\
8 & $>71$ & 13 & 7,83 \\
\hline & Jumlah & 166 & 100,00 \\
\hline
\end{tabular}

Sumber: Data dari Ketua RW 4, tahun 2018

Berdasarkan tabel 4.2 dapat dilihat bahwa penduduk yang paling banyak adalah penduduk dengan kategori umur $10-20$

\begin{tabular}{rlrr}
\hline N & Jenis Mata Pencaharian & $\begin{array}{r}\text { Jumlah } \\
\text { (orang) }\end{array}$ & $(\%)$ \\
\hline 1 & Karyawan swasta & 20 & 12,04 \\
2 & Belum / tidak bekerja & 30 & 18,07 \\
3 & Guru & 3 & 1,80 \\
4 & Wiraswasta & 19 & 11,44 \\
5 & Petani / pekebun & 29 & 17,46 \\
6 & PNS & 9 & 5,42 \\
7 & Pedagang & 4 & 2,40 \\
8 & Mengurus rumah tangga & 8 & 4,81 \\
9 & Pelajar / mahasiswa & 28 & 16,86 \\
10 & Perdagangan & 6 & 3,61 \\
11 & Tukang batu & 1 & 0,60 \\
12 & Perangkat desa & 1 & 0,60 \\
13 & Pensiunan & 3 & 1,80 \\
14 & Buruh tani / perkebunan & 3 & 1,80 \\
15 & Buruh harian lepas & 1 & 0,60 \\
17 & Tukang kayu & 1 & 0,60 \\
\hline & $\quad$ Jumlah & 166 & 100,00 \\
\hline
\end{tabular}

tahun yaitu sebanyak 28 jiwa
$(16,86 \%)$ dan yang sedikit yaitu dengan kategori umur > 71 tahun sebanyak 13 jiwa $(7,83 \%)$.

b. Jumlah penduduk di RT 2 RW 5 dan RT 3 RW 4 Desa Bodaskarangjati Menurut Mata Pencaharian

Tabel 4.3: Jumlah Penduduk Menurut Mata Pencaharian Di Desa Bodaskarangjati RT 2 RW 5 Kabupaten Purbalingga Tahun 2018

\begin{tabular}{|c|c|c|c|}
\hline No & $\begin{array}{l}\text { Jenis Mata } \\
\text { Pencahari-an }\end{array}$ & $\begin{array}{l}\text { Jumlah } \\
\text { (orang) }\end{array}$ & $(\%)$ \\
\hline 1 & $\begin{array}{l}\text { Karyawan } \\
\text { swasta }\end{array}$ & 40 & 11,11 \\
\hline 2 & $\begin{array}{l}\text { Belum / tidak } \\
\text { bekerja }\end{array}$ & 61 & 16,94 \\
\hline 3 & Guru & 5 & 1,38 \\
\hline 4 & Wiraswasta & 74 & 20,55 \\
\hline 5 & $\begin{array}{l}\text { Petani } \\
\text { pekebun }\end{array}$ & 55 & 15,27 \\
\hline 6 & PNS & 12 & 3,33 \\
\hline 7 & Pedagang & 11 & 3,05 \\
\hline 8 & $\begin{array}{l}\text { Mengurus } \\
\text { rumah tangga }\end{array}$ & 25 & 6,94 \\
\hline 9 & $\begin{array}{l}\text { Pelajar } \\
\text { mahasiswa }\end{array}$ & 63 & 17,5 \\
\hline 10 & Perdagangan & 6 & 1,66 \\
\hline 11 & Tukang batu & 1 & 0,27 \\
\hline 12 & $\begin{array}{l}\text { Perangkat } \\
\text { desa }\end{array}$ & 1 & 0,27 \\
\hline 13 & Pensiunan & 2 & 0,55 \\
\hline 14 & Dosen & 1 & 0,27 \\
\hline 15 & $\begin{array}{l}\text { Karyawan } \\
\text { honorer }\end{array}$ & 1 & 0,27 \\
\hline 17 & Perawat & 1 & 0,27 \\
\hline 18 & TNI & 1 & 0,27 \\
\hline & Jumlah & 360 & 100,00 \\
\hline
\end{tabular}

Sumber: Data dari Ketua RW 5, tahun 2018

Berdasarkan tabel 4.3 mata pencaharian penduduk RT $2 \mathrm{RW}$ 5 Desa Bodaskarangjati yang paling banyak adalah wiraswasta yaitu sebanyak 74 orang $(20,55 \%)$ dan mata pencaharian yang paling sedikit adalah tukang batu, perangkat desa, pensiunan, dosen, karyawan honorer, perawat dan TNI yang masingmasing mata pencaharian tersebut hanya berjumlah 1 orang $(0,27 \%)$.

Tabel 4.4: Jumlah Penduduk Menurut Mata Pencaharian Di Desa Bodaskarangjati RT 3 RW 4 Kabupaten Purbalingga Tahun 2018 
Sumber: Data dari Ketua RW 4 tahun 2018

Berdasarkan tabel 4.4 mata pencaharian penduduk RT $2 \mathrm{RW}$ 5 Desa Boodaskarangjati yang paling banyak adalah wiraswasta yaitu sebanyak 30 orang $(18,07 \%)$ dan mata pencaharian yang paling sedikit adalah tukang batu, perangkat desa, buruh harian lepas dan tukang kayu yang masing-masing mata pencaharian tersebut hanya berjumlah 1 orang $(0,60 \%)$.

B. Kadar Debu

1. Kadar Debu pada Pertukangan Kayu PK. Bodas Kusen di Desa Bodaskarangjati Kecamatan Rembang Kabupaten Purbalingga

Hasil pengukuran yang dilakukan selama 1 hari pada tanggal 27 April 2018 sebanyak 5 titik pengukuran, yaitu dimulai dari Pertukangan Kayu PK Bodas Kusen dan permukiman terdekat. Pengukuran kadar debu dilakukan pada pukul 12.50 WIB 14.25 WIB.

Tabel 4.5: Hasil Pengukuran Kadar Debu Selama 15 Menit Pada Pertukangan Kayu PK Bodas Kusen Di Desa Bodaskarangjati Kecamatan Rembang Kabupaten Purbalingga Tahun 2018

\begin{tabular}{crlcc}
\hline No & Tanggal & $\begin{array}{c}\text { Waktu } \\
\text { Pengu- } \\
\text { Kuran }\end{array}$ & Titik & $\begin{array}{c}\text { Kadar } \\
\text { Debu } \\
(\mathrm{mg} / \mathrm{m} \\
3\end{array}$ \\
\hline 1 & 27 & $12.50-$ & 1 & 0.491 \\
& $\begin{array}{rlc}\text { April } \\
2018\end{array}$ & 13.05 WIB & & \\
\hline \multicolumn{5}{c}{ Rata-Rata } \\
\hline
\end{tabular}

Keterangan:

Pengukuran pada titik pertama dilakukan di dalam area pertukangan kayu tepatnya di tengah-tengah dekat dengan aktivitas pekerja. Dengan didapatkan hasil sebesar 0,491 $\mathrm{mg} / \mathrm{m}^{3}$. Di ukur menggunakan alat dusttrek dengan durasi pengukuran selama 15 menit pada pukul $12.50-13.05$ WIB.

Tabel 4.6: Hasil Pengukuran Kadar Debu Pada Pertukangan Kayu PK Bodas Kusen (Setelah Dikonversikan Dari 15 Menit Ke 8 Jam) Di Desa Bodaskarangjati
Kecamatan Rembang Kabupaten Purbalingga Tahun 2018

Berdasarkan Tabel 4.5 dan Tabel 4.6 Diatas dapat diketahui bahwa hasil rata-rata pengukuran kadar debu di Pertukangan Kayu PK Bodas Kusen di Desa Bodaskarangjati Kecamatan Rembang Kabupaten Purbalingga yang belum dikonversikan dengan rata-rata kadar debu sebesar 0,491 $\mathrm{mg} / \mathrm{m}^{3}$ dan setelah dikonversikan yaitu sebesar $15,712 \mathrm{mg} / \mathrm{m}^{3}$.

Peneliti juga melakukan penelitian terhadap beberapa parameter yang mempengaruhi kualitas udara khususnya pencemaran debu. Pengukuran tersebut antara lain, kecepatan angin, cuaca, suhu dan kelembaban.

Hasil pengukuran tersebut yaitu sebagai berikut:

Tabel 4.7: Hasil Rata-Rata Pengukuran Kecepatan Angin, Cuaca, Suhu Dan Kelembaban Pada Pertukangan Kayu PK Bodas Kusen Di Desa Bodaskarangjati Kecamatan Rembang Kabupaten Purbalingga Tahun 2018

\begin{tabular}{|c|c|c|c|c|c|c|}
\hline No & $\begin{array}{c}\text { Titik } \\
\text { Penguk } \\
\text { ur-an }\end{array}$ & $\begin{array}{r}\text { Kecepa } \\
\text {-tan } \\
\text { Angin } \\
(\mathrm{M} / \mathrm{S})\end{array}$ & Cuaca & $\begin{array}{l}\text { Suhu } \\
\left({ }^{\circ} \mathrm{c}\right)\end{array}$ & $\begin{array}{l}\text { Kele } \\
\text { mba } \\
\text { ban } \\
(\%)\end{array}$ & $\begin{array}{c}\text { Arah } \\
\text { Angi } \\
-n\end{array}$ \\
\hline 1 & 1 & 0,0 & Cerah & 32 & 52 & $180^{\circ}$ \\
\hline & $\begin{array}{c}\text { Rata- } \\
\text { rata }\end{array}$ & 0,0 & Cerah & 32 & 52 & $180^{\circ}$ \\
\hline & & \multicolumn{5}{|c|}{$\begin{array}{l}\text { Pada pengukuran titik pertama } \\
\text { dihasilkan kecepatan angin } \\
\text { sebesar } 0,0 \mathrm{~m} / \mathrm{s} \text {. Hal ini karena } \\
\text { pada titik pertama dilakukan } \\
\text { pengukuran pada ruang kerja } \\
\text { yang sedikit tertutup. }\end{array}$} \\
\hline
\end{tabular}

2. Kadar debu pada permukiman yang terdekat dengan Pertukangan Kayu PK Bodas Kusen di Desa Bodaskarangjati Kecamatan Reembang Kabupaten Purbalingga

Hasil pengukuran yang dilakukan selama 1 hari pada tanggal 27 April 2018 sebanyak 5 titik pengukuran, yaitu dimulai dari Pertukangan Kayu PK Bodas Kusen dan permukiman terdekat. Pengukuran kadar debu dilakukan pada pukul 12.50 WIB 14.15 WIB.

Tabel 4.8: Hasil Pengukuran Kadar Debu Selama 15 Menit Pada Permukiman Yang Terdekat Dengan Pertukangan Kayu PK Bodas Kusen Di Desa Bodaskarangjati Kecamatan 
Rembang Kabupaten Purbalingga Tahun 2018

\begin{tabular}{|c|c|c|c|c|c|}
\hline No & $\begin{array}{c}\text { Tang } \\
\text { gal }\end{array}$ & $\begin{array}{c}\text { Waktu } \\
\text { Pengukur } \\
\text { an }\end{array}$ & Titik & $\begin{array}{c}\text { Kadar } \\
\text { Debu } \\
\left(\mathrm{mg} / \mathrm{m}^{3}\right)\end{array}$ & $\begin{array}{c}\text { Kadar } \\
\text { Debu } \\
\left(\mu \mathrm{g} / \mathrm{m}^{3}\right)\end{array}$ \\
\hline \multirow[t]{3}{*}{1} & 27 & $13.10-$ & \multirow[t]{3}{*}{2} & \multirow[t]{3}{*}{0,282} & \multirow[t]{3}{*}{282} \\
\hline & April & 13.25 & & & \\
\hline & 2018 & WIB & & & \\
\hline \multirow[t]{3}{*}{2} & 27 & $13.30-$ & \multirow[t]{3}{*}{3} & \multirow[t]{3}{*}{0,362} & \multirow[t]{3}{*}{362} \\
\hline & April & 13.45 & & & \\
\hline & 2018 & WIB & & & \\
\hline \multirow[t]{3}{*}{3} & 27 & $13.50-$ & \multirow[t]{3}{*}{4} & \multirow[t]{3}{*}{0,322} & \multirow[t]{3}{*}{322} \\
\hline & April & 14.05 & & & \\
\hline & 2018 & WIB & & & \\
\hline \multirow[t]{4}{*}{4} & 27 & $14.10-$ & \multirow[t]{3}{*}{5} & \multirow[t]{3}{*}{0,302} & \multirow[t]{3}{*}{302} \\
\hline & April & 14.25 & & & \\
\hline & 2018 & WIB & & & \\
\hline & & $\begin{array}{l}\text { Rata- } \\
\text { Rata }\end{array}$ & & 0,317 & 317 \\
\hline
\end{tabular}

Keterangan :

a. Pengukuran pada titik kedua dilakukan di sebelah timur pertukangan kayu PK Bodas Kusen tepatnya di dekat rumah warga dan DAMIU Bio Samfalaf. Dengan didapatkan hasil sebesar $0,282 \mathrm{mg} / \mathrm{m}^{3}$ atau $282 \mu \mathrm{g} / \mathrm{m}^{3}$. Di ukur menggunakan alat dusttrek dengan durasi pengukuran selama 15 menit pada pukul 13.10 - 13.25 WIB.

b. Pengukuran pada titik ketiga dilakukan di sebelah utara pertukangan kayu atau lebih tepatnya permukiman yang terdekat dengan pertukangan kayu PK Bodas Kusen $( \pm 5 \mathrm{~m}$ dari pertukangan kayu tersebut). Dengan didapatkan hasil sebesar $0,362 \mathrm{mg} / \mathrm{m}^{3}$ atau $362 \mu \mathrm{g} / \mathrm{m}^{3}$. Di ukur menggunakan alat dusttrek dengan durasi pengukuran selama 15 menit pada pukul 13.30 - 13.45 WIB.

c. Pengukuran pada titik ke empat dilakukan di dekat rumah warga tepatnya di sebelah utara pertukangan kayu atau di pinggir jalan raya dengan jarak $\pm 15 \mathrm{~m}$ dari pertukangan kayu PK Bodas Kusen sehingga kemungkinan ada debu yang bukan berasal dari aktivitas pertukangan kayu tersebut. Dengan didapatkan hasil sebesar $0,322 \mathrm{mg} / \mathrm{m}^{3}$ atau $322 \mu \mathrm{g} / \mathrm{m}^{3}$. Di ukur menggunakan alat dusttrek dengan durasi pengukuran selama 15 menit pada pukul $13.50-14.05$ WIB. d. Pengukuran pada titik ke lima dilakukan di sebelah selatan pertukangan kayu tepatnya di pinggir jalan raya, di depan rumah warga dengan jarak terjauh dari pertukangan kayu PK Bodas Kusen yaitu $\pm 20 \mathrm{~m}$ dari pertukangan kayu tersebut. Karena pengukuran dilakukan di dekat jalan raya maka kemungkinan juga terdapat debu yang bukan berasal dari aktivitas pertukangan kayu tersebut. Dengan didapatkan hasil sebesar $0,302 \mathrm{mg} / \mathrm{m}^{3}$ atau $302 \mu \mathrm{g} / \mathrm{m}^{3}$. Di ukur menggunakan alat dusttrek dengan durasi pengukuran selama 15 menit pada pukul $14.10-14.25$ WIB.

Tabel 4.9: Hasil Pengukuran Kadar Debu Pada Permukiman Yang Terdekat Dengan Pertukangan Kayu PK Bodas Kusen (Setelah Dikonversikan Dari 15 Menit Ke 24 Jam) Di Desa Bodaskarangjati Kecamatan Rembang Kabupaten Purbalingga Tahun 2018

\begin{tabular}{|c|c|c|c|c|c|}
\hline No & $\begin{array}{c}\text { Tang } \\
\text { gal }\end{array}$ & $\begin{array}{c}\text { Waktu } \\
\text { Penguk } \\
\text { uran }\end{array}$ & Titik & $\begin{array}{c}\text { Kadar } \\
\text { Debu } \\
\left(\mathrm{mg} / \mathrm{m}^{3}\right. \\
)\end{array}$ & $\begin{array}{c}\text { Kadar } \\
\text { Debu } \\
\left(\mu \mathrm{g} / \mathrm{m}^{3}\right)\end{array}$ \\
\hline 1 & $\begin{array}{c}27 \\
\text { April } \\
2018\end{array}$ & $\begin{array}{l}13.10- \\
13.25 \\
\text { WIB }\end{array}$ & 2 & 27,072 & 27.072 \\
\hline 2 & $\begin{array}{c}27 \\
\text { April } \\
2018\end{array}$ & $\begin{array}{l}13.30- \\
13.45 \\
\text { WIB }\end{array}$ & 3 & 34,752 & 34.752 \\
\hline 3 & $\begin{array}{c}27 \\
\text { April } \\
2018\end{array}$ & $\begin{array}{l}13.50- \\
14.05 \\
\text { WIB }\end{array}$ & 4 & 30,912 & 30.912 \\
\hline \multirow[t]{2}{*}{4} & $\begin{array}{c}27 \\
\text { April } \\
2018\end{array}$ & $\begin{array}{l}14.10- \\
14.25 \\
\text { WIB }\end{array}$ & 5 & 28,992 & 28.992 \\
\hline & & $\begin{array}{l}\text { Rata- } \\
\text { Rata }\end{array}$ & & 30,432 & 30.432 \\
\hline
\end{tabular}

Berdasarkan Tabel 4.8 dan Tabel 4.9 Diatas dapat diketahui bahwa hasil ratarata pengukuran kadar debu di permukiman yang terdekat dengan Pertukangan Kayu PK Bodas Kusen di Desa Bodaskarangjati Kecamatan Rembang Kabupaten Purbalingga yang belum dikonversikan dengan rata-rata kadar debu sebesar $0,317 \mathrm{mg} / \mathrm{m}^{3}$ atau 317 $\mu \mathrm{g} / \mathrm{m}^{3}$ dan setelah dikonversikan ke 24 jam yaitu sebesar $30,432 \mathrm{mg} / \mathrm{m}^{3}$ atau $30.432 \mu \mathrm{g} / \mathrm{m}^{3}$.

Peneliti juga melakukan penelitian terhadap beberapa parameter yang mempengaruhi kualitas udara khususnya pencemaran debu. Pengukuran tersebut antara lain, kecepatan angin, cuaca, suhu 
dan kelembaban. Hasil pengukuran tersebut yaitu sebagai berikut:

Tabel 4.10: Hasil Rata-Rata Pengukuran Kecepatan Angin, Cuaca, Suhu Dan Kelembaban Di Pertukangan Kayu PK Bodas Kusen Desa Bodaskarangjati Kecamatan Rembang Kabupaten Purbalingga Tahun 2018

\begin{tabular}{|c|c|c|c|c|c|c|}
\hline No & $\begin{array}{c}\text { Titik } \\
\text { Penguku } \\
\text {-ran }\end{array}$ & $\begin{array}{c}\text { Kecepat } \\
\text {-an } \\
\text { Angin } \\
(\mathrm{M} / \mathrm{S})\end{array}$ & Cuaca & $\begin{array}{l}\text { Suhu } \\
\left({ }^{\circ} \mathrm{c}\right)\end{array}$ & $\begin{array}{c}\text { Kelembab- } \\
\text { an }(\%)\end{array}$ & $\begin{array}{r}\text { Arah } \\
\text { Angin }\end{array}$ \\
\hline 1 & 2 & 2,10 & Cerah & 34 & 52,0 & $0^{\circ}$ \\
\hline 2 & 3 & 0,30 & Cerah & 33 & 58,0 & $180^{\circ}$ \\
\hline 3 & 4 & 1,40 & Cerah & 32 & 59,0 & $180^{\circ}$ \\
\hline 4 & 5 & 0,30 & Cerah & 29 & 62,0 & $0^{\circ}$ \\
\hline & $\begin{array}{l}\text { Rata- } \\
\text { rata }\end{array}$ & 0,82 & Cerah & 32 & 57,7 & $90^{\circ}$ \\
\hline
\end{tabular}

Keterangan :

a. Pada pengukuran titik kedua di sebelah timur Pertukangan Kayu PK Bodas Kusen dihasilkan kecepatan angin sebesar $2,1 \mathrm{~m} / \mathrm{s}$ dan arah angin sebesar $0^{\circ}$.

b. Pada pengukuran titik ke tiga di sebelah utara Pertukangan Kayu PK Bodas Kusen dengan jarak \pm 5 meter dari pertukangan kayu dihasilkan kecepatan angin sebesar $0,3 \mathrm{~m} / \mathrm{s}$ dan arah angin sebesar $180^{\circ}$.

c. Pada pengukuran titik ke empat di sebelah utara Pertukangan Kayu PK Bodas Kusen dengan jarak \pm 10 meter dar ertukangan kayu dihasilkan kecepatan angin sebesar $1,4 \mathrm{~m} / \mathrm{s}$ dan arah angin sebesar $180^{\circ}$

d. Pada pengukuran titik ke lima di sebelah selatan Pertukangan Kayu PK Bodas Kusen dihasilkan kecepatan angin sebesar $0,3 \mathrm{~m} / \mathrm{s}$ dan arah angin sebesar $0^{\circ}$.

3. Upaya pengendalian pencemaran debu pada pertukangan kayu PK Bodas Kusen

Pertukangan Kayu PK Bodas

Kusen Desa Bodaskarangjati Kecamatan Rembang Kabupaten Purbalingga belum melakukan pengendalian pencemaran kadar debu yang telah dihasilkan dari kegiatan pertukangan kayu tersebut.

4. Upaya pengendalian pencemaran debu pada permukiman terdekat atau lingkungan pertukangan kayu PK Bodas Kusen

$$
\text { Pertukangan Kayu PK Bodas }
$$

Kusen Desa Bodaskarangjati

Kecamatan Rembang Kabupaten

Purbalingga belum melakukan pengendalian pencemaran kadar debu yang telah dihasilkan dari kegiatan pertukangan kayu tersebut pada permukiman yang terdekat dengan pertukangan kayu.

\section{IV.Pembahasan}

A. Data Umum di Pertukangan Kayu PK Bodas Kusen Desa Bodaskarangjati Kecamatan Rembang Kabupaten Purbalingga

Pertukangan kayu PK Bodas Kusen terletak di Desa Bodaskarangjati RT 2 RW 5 Kecamatan Rembang Kabupaten Purbalingga dengan luas lahan $287 \mathrm{~m} 2$, tetapi yang digunakan sebagai tempat pertukangan kayu $\pm 100 \mathrm{~m} 2$ dan selebihnya digunakan untuk tempat tinggal.

Pertukangan Kayu PK Bodas Kusen berdiri sejak tahun 2003 silam. Pemiliknya bernama Bapak Karyono S Karjaya yang berasal dari Indramayu, Jawa Barat. Beliau menyewa tanah di Desa Bodaskarangjati RT 2 RW 5 untuk memulai usahanya. Beliau mempekerjakan 6 orang pekerja sebagai tukang dengan sistem kerja borongan. Dan para pekerjanya pun kebanyakan berasal dari Indramayu, Jawa Barat.

Kegiatan pertukangan kayu berpotensi menghasilkan pencemaran udara berupa debu kayu. Apabila debu kayu tersebut terhirup secara terus menerus maka dapat menyebabkan gangguan yang serius terhadap kesehatan yaitu pada saluran pernapasan.

B. Data Khusus di Pertukangan Kayu PK Bodas Kusen Desa Bodaskarangjati Kecamatan Rembang Kabupaten Purbalingga

1. Kondisi pada Pertukangan Kayu PK Bodas Kusen di Desa Bodaskarangjati Kecamatan Rembang Kabupaten Purbalingga

Berdasarkan hasil observasi lingkungan yang peneliti lakukan di lingkungan Pertukangan Kayu PK Bodas Kusen di Desa Bodaskarangjati Kecamatan Rembang Kabupaten Purbalingga didapatkan hasil yaitu kondisi lingkungan pertukangan kayu masih kurang baik. Hal tersebut dilihat dari konstruksi bangunan yang tidak permanen, ventilasi yang tidak baik, tidak terdapat pepohonan yang rindang disekitar bangunan, jarak antara pertukangan kayu dengan permukiman kurang dari 100 meter 
dan tidak terdapat cerobong penghisap debu pada bangunan.

Pihak pertukangan kayu tidak memiliki prosedur kerja. Hal ini dibuktikan dengan tidak mewajibkan pekerjanya untuk menggunakan alat pelindung diri (APD) seperti masker guna menghindari kontak langsung dengan debu kayu. Pekerja menggunakan masker merupakan atas dasar kesadaran diri sendiri.Tetapi juga ada beberapa pekerja yang tidak menggunakan APD berupa masker. Dengan alasan kurang nyaman apabila bekerja sambil menggunakan masker. Ada juga yang menggunakan APD berupa masker hanya pada kegiatan tertentu saja, seperti kegiatan menyerut, mengamplas atau kegiatan lainnya yang menghasilkan debu lumayan banyak.

Jam kerja yang terdapat di Pertukangan Kayu PK Bodas Kusen Desa Bodaskarangjati Kecamatan Rembang Kabupaten Purbalingga adalah tidak menentu karena pada pertukangan kayu tersebut menerapkan sistim kerja borongan. Pekerja mulai bekerja pada pukul 07.00 WIB sedangkan selesainya tidak menentu, ada yang selesai pukul 17.00 WIB dan ada juga yang selesai pikul 17.30 WIB. Sedangkan waktu istirahat hanya diberikan pada waktu sholat dzuhur dan ashar.

2. Hasil Pengukuran Kadar Debu dan Lingkungan Fisik di Pertukangan Kayu PK. Bodas Kusen di Desa Bodaskarangjati Kecamatan Rembang Kabupaten Purbalingga dan lingkungan

Kadar debu pada pertukangan kayu PK Bodas Kusen di dapatkan hasil rata-rata keseluruhan kadar debu selama 15 menit pengukuran sebesar 0,491 mg/m3 dan setelah dikonversikan dari 15 menit ke 8 jam yaitu sebesar $15,712 \mathrm{mg} / \mathrm{m} 3$. Setelah dibandingkan dengan Peraturan Menteri Kesehatan RI No 70 Tahun 2016 Tentang Standar Persyaratan Kesehatan Lingkungan Kerja Industri yaitu $10 \mathrm{mg} / \mathrm{m} 3$. Maka dapat disimpulkan bahwa debu kayu yang dihasilkan oleh pertukangan kayu PK Bodas Kusen adalah melebihi nilai ambang batas.

3. Upaya penanggulangan kadar debu di Pertukangan Kayu PK Bodas
Kusen di Desa Bodaskarangjati Kecamatan Rembang Kabupaten Purbalingga

Upaya penanggulangan kadar debu pada pertukangan kayu PK Bodas Kusen dapat dilakukan dengan cara:

a. Meminimalisir pencemar pada sumber/emisi yaitu dengan:

Ruang kerja Pertukangan Kayu PK Bodas Kusen dibuat tertutup dan berventilasi baik serta diberi cerobong asap yang tinggi \pm 10 meter dari tinggi bangunan agar tidak terjadi peencemaran udara di lingkungan permukiman setempat.

b. Penangkapan debu, yaitu dengan cara:

Menambah fasilitas berupa penghisap debu seperti filter, cyclone mapun blower untuk menghisap debu kayu yang telah dihasilkan dari kegiatan pertukangan kayu tersebut guna meminimalisir terbangnya debu kayu yang dihasilkan agar tidak langsung ke permukiman terdekat.

c. Lokalisasi industri penghasil bahan cemaran udara pada daerah yang jauh dari permukiman, sesuai rencana tata guna ruang. Lokalisasi industri dimaksudkan agar cemaran gas dan debu yang dihasilkan industri dapat diminimalisir agar tidak menyebar ke permukiman.

C. Data Khusus di permukiman yang terdekat dengan Pertukangan Kayu PK Bodas Kusen Desa Bodaskarangjati Kecamatan Rembang Kabupaten Purbalingga

1. Kondisi pada permukiman terdekat dengan pertukangan kayu PK Bodas Kusen Desa Bodaskarangjati Kecamatan Rembang Kabupaten Purbalingga

Pertukangan kayu PK Bodas Kusen terletak di tengah-tengah permukiman antara RT 2 RW 5 dan RT 3 RW 4 Desa Bodaskarangjati Kecamatan Rembang Kabupaten Purbalingga. RT 2 RW 5 terdapat jumlah penduduk sebanyak 360 jiwa yang terdiri dari 182 jiwa laki-laki dan 178 jiwa perempuan serta 108 KK. Sedangkan pada RT 3 RW 4 jumlah penduduknya sebesar 166 jiwa yang terdiri dari 75 jiwa laki- 
laki dan 91 jiwa perempuan serta 52 KK.

2. Hasil Pengukuran Kadar Debu dan Lingkungan Fisik di permukiman yang terdekat dengan Pertukangan Kayu PK Bodas Kusen di Desa Bodaskarangjati Kecamatan Rembang Kabupaten Purbalingga

Kadar debu pada pertukangan kayu PK Bodas Kusen di dapatkan hasil rata-rata keseluruhan kadar debu selama 15 menit pengukuran sebesar $0,317 \quad \mathrm{mg} / \mathrm{m} 3$ atau 317 $\mu \mathrm{g} / \mathrm{m} 3$ dan setelah dikonversikan ke 24 jam yaitu sebesar 30,432 $\mathrm{mg} / \mathrm{m} 3$ atau $30.432 \mu \mathrm{g} / \mathrm{m} 3$. Setelah dibandingkan dengan Peraturan Menteri Kesehatan Ri Nomor 1077/MENKES/PER/V/2011

Tentang Pedoman Penyehatan Udara Dalam Ruang Rumah yaitu $\leq 70$ $\mu \mathrm{g} / \mathrm{m} 3$.Maka dapat disimpulkan bahwa debu kayu yang dihasilkan oleh pertukangan kayu PK Bodas Kusen adalah melebihi nilai ambang batas

3. Upaya penanggulangan kadar debu di permukiman terdekat dengan Pertukangan Kayu PK. Bodas Kusen di Desa Bodaskarangjati Kecamatan Rembang Kabupaten Purbalingga

Upaya pengendalian yang tepat yang dapat dilakukan pada permukiman terdekat dengan pertukangan kayu adalah:

a. Penanaman pohon. Tanaman di depan rumah juga dapat menahan debu yang beterbangan di jalan. Suhu dan kelembaban lingkungan sekitar menjadi bisa terjaga baik dengan adanya tanaman. (Tri Cahyono, 2017 h, 219)

b. Memasang penangkap debu (elektro presipitator) pada ventilasi rumah dan dibersihkan secara berkala. (Peraturan Menteri Kesehatan RI Nomor 1077/ MENKES/ PER/ V/ 2011 Tentang Pedoman Penyehatan Udara Dalam Ruang Rumah)

c. Menanam tanaman di sekeliling rumah untuk mengurangi masuknya debu kedalam rumah. (Peraturan Menteri Kesehatan RI Nomor 1077/ MENKES/ PER/ V/ 2011 Tentang Pedoman Penyehatan Udara Dalam Ruang Rumah)
Pencegahan pencemaran debu sebaiknya lebih diperhatikan mengingat pencemaran yang dihasilkan pertukangan kayu tersebut cukup tinggi dan berbahaya bagi kesehatan. Ada beberaa cara upaya pengendalian pencemaran debu yang dapat dilakukan diantaranya:

1) Pembersihan perabot rumah tangga secara rutin untuk mengurangi partikel debu yang menempel pada perabot rumah.

2) Penyiraman menggunakan air pada halaman rumah dan tanaman yang ada disekitar rumah untuk mengurangi debu yang berterbangan.

\section{Kesimpulan}

1. Kadar debu pada Pertukangan Kayu PK Bodas Kusen Desa Bodaskarangjati Kecamatan Rembang Kabupaten Purbalingga pada pengukuran selama 15 menit adalah $0,491 \mathrm{mg} / \mathrm{m}^{3}$ sedangkan hasil pengukuran kadar debu yang telah dikonversikan dari 15 menit ke 8 jam adalah $15,712 \mathrm{mg} / \mathrm{m}^{3}$.

2. Kadar debu pada permukiman yang terdekat dengan Pertukangan Kayu PK Bodas Kusen Desa Bodaskarangjati Kecamatan Rembang Kabupaten Purbalingga pada pengukuran selama 15 menit didapatkan hasil tertinggi sebesar $0,362 \mathrm{mg} / \mathrm{m}^{3}$ atau $362 \mu \mathrm{g} / \mathrm{m}^{3}$, hasil terendah sebesar $0,302 \mathrm{mg} / \mathrm{m}^{3}$ atau 302 $\mu \mathrm{g} / \mathrm{m} 3$ dan didapatkan hasil rataratasebesar $0,317 \mathrm{mg} / \mathrm{m}^{3}$ atau $317 \mu \mathrm{g} / \mathrm{m}^{3}$ sedangkan setelah dikonversikan ke 24 jam di dapatkan hasil tertinggi sebesaryaitu sebesar $30,432 \mathrm{mg} / \mathrm{m}^{3}$ atau $30.432 \mu \mathrm{g} / \mathrm{m}^{3}$, hasil terendah sebesar $28,991 \mathrm{mg} / \mathrm{m}^{3}$ atau $28.991 \mu \mathrm{g} / \mathrm{m}^{3}$ dan didapatkan hasil rata-rata sebesar 30,432 $\mathrm{mg} / \mathrm{m}^{3}$ atau $30.432 \mu \mathrm{g} / \mathrm{m}^{3}$.

3. Upaya pengendalian pencemaran debu pada pertukangan kayu PK Bodas Kusen

Pertukangan Kayu PK Bodas Kusen Desa Bodaskarangjati Kecamatan Rembang Kabupaten Purbalingga belum melakukan pengendalian pencemaran kadar debu yang telah dihasilkan dari kegiatan pertukangan kayu tersebut.

4. Upaya pengendalian pencemaran debu pada permukiman terdekat atau lingkungan pertukangan kayu PK Bodas Kusen 
Pertukangan Kayu PK Bodas Kusen Desa Bodaskarangjati Kecamatan Rembang Kabupaten Purbalingga belum melakukan pengendalian pencemaran kadar debu yang telah dihasilkan dari kegiatan pertukangan kayu tersebut pada permukiman yang terdekat dengan pertukangnan kayu.

\section{VI.Daftar Pustaka}

Indonesia. Departemen Kesehatan Republik Indonesia. 1988. Petunjuk Pengukuran Kualitas Udara. Jakarta: Direktorat Jenderal Pemberantasan Penyakit Menular dan Penyehatan Lingkungan Pemukiman

Indonesia.Depkes RI. 1994. Pedoman Pengendalian Pencemaran Udara Ambien Yang Berhubungan Dengan Kesehatan Masyarakat. Jakarta: direktorat jenderal PPM \& PLP Depkes RI

Moestikahadi Soedomo. 2001. Tentang Pencemaran Udara. Bandung: ITB

Peraturan Menteri Negara Lingkungan Hidup No 12 Tahun 2010 Tentang Pelaksanaan Pengendalian Pencemaran Udara Di Daerah
Peraturan Menteri Kesehatan RI No 70 Tahun 2016 Tentang Stndar dan Persyratan Kesehatan Lingkungan Kerja Industri

Peraturan Menteri Kesehatan RI No 1077 / MENKES / PER / V / 2011 Tentang Penyehatan Udara Dalam Ruang Rumah

Peraturan Menteri Tenaga Kerja Dan Transigrasi No PER.13/ME/X/2011 Tentang Nilai Ambang Batas Faktor Fisika dan Faktor Kimia di Tempat Kerja

Peraturan Pemerintah RI No 41 Tahun 1999. Tentang Pengendalian Pencemaran Udara

Suma'mur. 2013. Higiene Perusahaan Dan Kesehatan Kerja (HIPERKES). Jakarta: Sagung Seto

Tri Cahyono. 2017. Penyehatan Udara. Yogyakarta: Andi

2018.Tentang Panduan Penulisan Tugas Akhir D3 Kesehatan Lingkungan Purwokerto 